\title{
Phytochemical and Antioxidant Capability of Vitex doniana (Black Plum) Fruit
}

\author{
C. Imoisi ${ }^{1 *}$, J.U. Iyasele ${ }^{1}$ and S.A. Okhale ${ }^{2}$ \\ ${ }^{1}$ Department of Chemistry, University of Benin, Benin City, Nigeria. P.M.B.1154, Benin City, Nigeria. \\ ${ }^{2}$ Departments of Medicinal Plant Research and Traditional Medicine, National Institute for Pharmaceutical \\ Research and Development (NIPRD), Garki, Abuja, Nigeria. \\ *Correspondents Author: imoisi.chinyere @ gmail.com, Tel: +2347030746386 \\ Received 11 January 2021; accepted 27 January 2021, published online 05 February 2021
}

\begin{abstract}
The search for more nutritionally active sources among forest products has called for the analysis of the phytochemical content and antioxidant activity of Vitex doniana (black plum) sweet fruit. Although, Vitex doniana sweet fruit had been known to be very useful among people across tropical Africa and beyond, but there is lack of adequate data on its phytochemical and antioxidant composition. The fresh fruits of Vitex doniana sweet were collected from several randomly selected trees in a farm site in Uromi metropolis, Esan North-East Local Government Area of Edo state and then processed into an extract in form of syrup. The phytochemical and antioxidant profile of Vitex doniana sweet fruit were investigated to ascertain its health benefits. The antioxidant activity was done by measuring the scavenging effect of the fruit and ascorbic acid on 2, 2-diphenyl-1-picrylhydrazyl (DPPH) radical. The scavenging ability of the fruit showed a concentrationdependent activity profile. It increased with an increase in concentrations. The $\mathrm{IC}_{50}$ value of the fruit was found to be $245.8 \mu \mathrm{g} / \mathrm{mL}$ and that of ascorbic acid $2.175 \mu \mathrm{g} / \mathrm{mL}$, indicating that the fruit has very little antioxidant activity comparable to ascorbic acid (control). The study also revealed that the fruit contains tannins, saponins, cardiac glycosides, alkaloids, flavonoids, terpenoids and steroids.

Keywords: Antioxidant, Phytochemicals, Ascorbic acid, Scavenging, Fruit, Vitex doniana
\end{abstract}

\section{Introduction}

Herbal remedy is garnering attractiveness in emerging countries. Herbal medications are time and again thought to be not hurtful since they are natural and free of negative consequence [1]. This surge in acceptance and the dearth of methodical studies on their effectiveness and safety have risen up apprehensions concerning the harmfulness and adverse effects of these therapies [2]. Study attention has concentrated on countless herbs that retain hypolipidemic, antiplatelet, antitumor, or immune-stimulating characteristics that might be beneficial adjuncts in facilitating to decrease the threat of cancer and cardiovascular illness [3]. Presently, there is an unending world-wide green uprising which is chiefly premised on the conviction that herbal medicines are benign and less harmful to the human body than artificial drugs [4]. Herbal drug shows essential role in sustaining the well-being and affluence of menfolk. Bulk of world's populace utilise herbal treatments. The World Health Organization (WHO) rumors that about 21,000 vegetation have been utilised for therapeutic purposes [5]. Herbs have stood the investigation of time for their welfare, efficiency, social suitability and marginal side special effects [6]. With increasing stress on improving traditional herbal food resources in
Nigeria, there is the requisite for improved understanding of available flowers plus the severally underutilized classes. Black plum is a vegetal extensively used by numerous societies in Nigeria for countless purposes, as well as manufacture of wine and jam. Ready mature black plum fruitlets for diet usage, usually are gathered from the ground instead of plucked [7]. Vitex doniana signifies some of our abandoned underutilized forestry assets. Although major research on the health benefits of plant-rich diets has laid emphasis on established vitamins, the current data are controversial and the drive towards identification of more constituents and plant food sources continues [8]. In addition, the economic importance of Vitex doniana is yet to be exploited to its maximum regardless of the documented uses. Black plum of the genus verbanacae is a shrub produce that breeds in open woodland and grassland regions of hot Africa; it is the most predominant of the Vitex species in West Africa. It yields fruitlets which are like plum, sweet-smelling and fit for human consumption. The fruitlet is green when matured and transforms to dark brown when completely ripe, with the flesh surrounding a hard stone encompassing 1 to 4 seeds. It is grassland specie and hence can originate in northern, western as well as eastern 
Nigeria. Flowers as well as other components of natural source have being useful all over the world for mortal and animal health maintenance for a very long time. This is particularly in Africa where underdevelopment and dearth have made a huge proportion of the populaces depend more or less totally on traditional therapeutic practices and folkloric application of vegetation [9].

The efficiency of most traditional herbal therapies has been displayed by quite a lot of researchers. One of such vegetal popular for it widespread usage in Africa natural folklore is V. Doniana Sweet. The herb is indigene to Botswana, Nigeria, Kenya, Ethiopia, Namibia, Lesotho, Senegal, Niger, South Africa, Somalia, Tanzania, Sudan, Zambia and Uganda. It is locally known as dinya (Hausa), Vitex (English), oori-nla (Yoruba) and ucha koro (Igbo) [10]. In traditional medicine, several portions of the vegetables are applied as medication for communicable conditions [11]. For instance the leaf, the bark, dried and fresh fruit serve as ingredients in many preparations to treat or heal diseases including conjunctivitis, headache, stiffness, measles, rash, fever, chickenpox, hemiplegia, respiratory diseases, ankylostomiasis, rachitis, gastro-intestinal disorders, jaundice, kidney troubles, leprosy, liver diseases, bleeding after childbirth and diarrhea [11]. Vitex doniana is an important indigenous fruit or leafy vegetable in Africa [12]. The blackish extract developed by steaming the bark, foliage, root and/or fruits is used as ink and dye for apparels [12]. The general term, 'Vitex', is an ancient Latin designation for the species. Aside from the commercial significance of this vegetal in wood and timber production, not much investigation on its biochemical and antioxidant activity has been done. It is in the light of the above, that this research aim to connect scientific outcomes with many of these therapautic uses with the intentions of drawing more research attention to herb in trending lead/hit scenarios in drug finding. Black plum are brand-named as juicy seed bearing structure of blossoming vegetal that could be consumed as nutrition [13]. Fruitlets are not given the place they deserve in the food of Nigerians owing to lack mindfulness of their nutritious value, price and problems in storage and distribution [14]. The food of most rural and urban inhabitants is short in protein occasioning increased prevalence of malnourishment and increase in alimental diseases; a condition in which offspring and particularly expectant and lactating womenfolk are most vulnerable [15].

\section{Materials and Methods Chemicals}

All the chemicals/reagents used in the current research were of analytical grade and were purchased from Sigma Chemical Company (St. Louis, Missouri, USA).

\section{Plant Collection and Identification}

The collection and extraction was done using the method described by Aiwonegbe et al. [16]. The fresh fruits of black plum (Vitex doniana) (purple black in colour) (Fig. 1.3) (1500 fruits) weighing $3 \mathrm{~kg}$ were collected by picking ripe fruits that fell on the ground from several randomly selected trees in a farm site in Uromi, Esan-North East Local Government Area of Edo state on $28^{\text {th }}$ August, 2018 during fruiting season (JuneOctober, annually). The fruits were stored at (ambient temperature, 85\% Relative Humidity). The fruits were $2.8-3.2 \mathrm{~cm}$ in length, $1.2-1.4 \mathrm{~cm}$ in width and contained one hard conical seed each which is about 1.5-2.0 cm long and 1.0-1.2 cm wide. Quartering method [17] was used to select fruits for analysis. The plant was identified and authenticated by the Ethnobotanist in the Department of Medicinal Plant Research and Traditional Medicine (MPR\&TM) of the National Institute for Pharmaceutical Research and Development (NIPRD) Abuja, Nigeria. A reference voucher specimen number NIPRD/01/03/CCPF/384/3 was deposited at the herbarium of (NIPRD), Idu Industrial area, Abuja.

\section{Extraction of the Syrup from Vitex doniana Fruit}

Extraction was done using a method modified by Aiwonegbe et al. [16]. The fruits were kept under ambient temperature in the laboratory. The fruits were sorted to select the fresh ones and then cleansed to remove sand and other debris. Thereafter, portable water was used for washing the fruit pulp, and the thin epicarp was removed. The fruits were then milled through a $90 \mu \mathrm{m}$ sieve to press out the succulent mesocarp and separate the stony seed from the pericarp. In a waring blender for a few seconds, the fruit pulp (1000 g) was blended with $1400 \mathrm{~mL}$ of distilled water in a waring blender for 10 seconds. The syrup which weighed $1.5 \mathrm{~kg}$ was immediately bottled in an airtight container. The syrup was stored in the refrigerator at $4^{\circ} \mathrm{C}$ before analysis. 


\section{Phytochemicals Screening}

The Existence of these secondary metabolites in the Vitex doniana fruit syrup was determined via standard methods [18].

\section{Alkaloids Determination}

By acid alcohol, syrup of $0.5 \mathrm{~g}$ was diluted into 10 $\mathrm{mL}$, heated and also strained. Dilute ammonia of 2 $\mathrm{mL}$ was mixed with $5 \mathrm{~mL}$ of the filtrate. To obtain the base which is alkaloidal, chloroform of $5 \mathrm{~mL}$ was then put and stirred gently. With acetic acid of $10 \mathrm{~mL}$, the layer of chloroform was extracted. Then this was separated into dual parts. Dragendorff's reagent was put into one part and Mayer's reagent in the second. Reddish brown precipitate formation (with Dragendorff's reagent) or cream formation (with Mayer's reagent) was observed as optimistic test for the alkaloids occurrence.

\section{Test for Tannins and Polyphenols}

Into water in a test tube of $10 \mathrm{~mL}$, about $0.5 \mathrm{~g}$ of the syrup was heated and then sieved. A little droplet of $0.1 \%$ of ferricoride was put also detected for blue-black or a brownish green coloration.

\section{Test for Terpenoids}

$0.5 \mathrm{~g}$ of the syrup was put onto $2 \mathrm{~mL}$ of chloroform. To form a layer, conc. $\mathrm{H}_{2} \mathrm{SO}_{4}(3 \mathrm{~mL})$ was judiciously put. The terpenoids existence is indicated by a brownish red coloration at the interface.

\section{Glycosides Determination}

$2 \mathrm{~mL}$ of Glacial acetic acid was used to treat the syrup, then 1 droplet of $\mathrm{FeCl}_{3}$ was added and conc. $\mathrm{H}_{2} \mathrm{SO}_{4}$ of $1 \mathrm{~mL}$. The presence of glycosides was showed by the presence of coloration that was brown.

\section{Flavonoids Determination}

To determine flavonoids, this procedure was used. Firstly, to one the portion of the filtrate, a little droplet of $1 \%$ aluminium hydroxide solution was put. The flavonoids existence was showed by a yellowish color.

Test for Saponins

In a test tube, to $0.5 \mathrm{~g}$ of syrup was added $5 \mathrm{~mL}$ of distilled water. Thereafter the solution was shaken and observed for a stable persistent froth. 3 drops of olive oil was mixed with the frothing and observed for the formation of an emulsion after been shaken.

\section{Steroids and Terpenoids Determination}

To $1 \mathrm{~g}$ individually of the syrup, a $9 \mathrm{~mL}$ quantity of ethanol was put and for a limited time, refluxed plus filtered. In a boiling water bath, the respective filtrates were concentrated to $2.5 \mathrm{~mL}$. To each of the concentrated solution distilled water of $5 \mathrm{~mL}$ was added, for $1 \mathrm{~h}$, each of the mixtures was allowed to stand. Using a separating funnel, each of the syrup was extracted with $2.5 \mathrm{~mL}$ of chloroform. In a test tube, each $0.5 \mathrm{~mL}$ of the chloroform extracts was judiciously put into $1 \mathrm{~mL}$ of conc. $\mathrm{H}_{2} \mathrm{SO}_{4}$ to form a lower layer. The occurrence of steroids was shown by a brownishred interface. On a water bath, to one more $0.5 \mathrm{~mL}$ each of the extract of chloroform was evaporated to dryness and for $10 \mathrm{~min}$ on a water bath, heated with $3 \mathrm{~mL}$ of conc. $\mathrm{H}_{2} \mathrm{SO}_{4}$. Terpenoids presence was shown by a grey colour.

\section{Antioxidant Activity Determination}

The scavenging effect of the syrup of Vitex doniana on DPPH radical was assessed using the method designated by Adamu et al. [19]. A solution of $0.1 \mathrm{mM}$ DPPH in methanol was made, and $1.0 \mathrm{~mL}$ of this solution was mixed with 3.0 $\mathrm{mL}$ of syrup in methanol containing 0.01-0.02 $\mathrm{mg} / \mathrm{mL}$ of the extract. The reaction mixture was vortexed painstakingly and leftward in the dark at ambient temperature for 30 minutes. The absorbance of the mix was measured spectrophotometrically at $517 \mathrm{~nm}$. Ascorbic acid was used as a reference standard. The capacity to scavenge DPPH radical was calculated by the following equations:

DPPH radical scavenging activity $(\%)=\left[\left(\mathrm{A}_{0}-\mathrm{A}_{1}\right) /\right.$ $\left.\left(\mathrm{A}_{0}\right)\right] \times 100$.

Where; $\mathrm{A}_{0}$ was the absorbance of DPPH radical + methanol

$\mathrm{A}_{1}$ was the absorbance of DPPH radical + sample extract.

The $50 \%$ inhibitory concentration value $\left(\mathrm{IC}_{50}\right)$ is specified as the actual concentration of the sample that is necessary to scavenge $50 \%$ of the DPPH free radical.

\section{Results and Discussion}


Phytochemicals

Vitex doniana

$\begin{array}{lr}\text { Alkaloids } & + \\ \text { Flavonoids } & + \\ \text { Saponins } & + \\ \text { Tannins } & + \\ \text { Steroids } & + \\ \text { Terpenoids } & + \\ \text { Cardiac glycosides } & + \\ \text { KEY: + = present, - = absent } & \end{array}$

+
+
+
+
+
+
+

: + = present, $-=$ absent

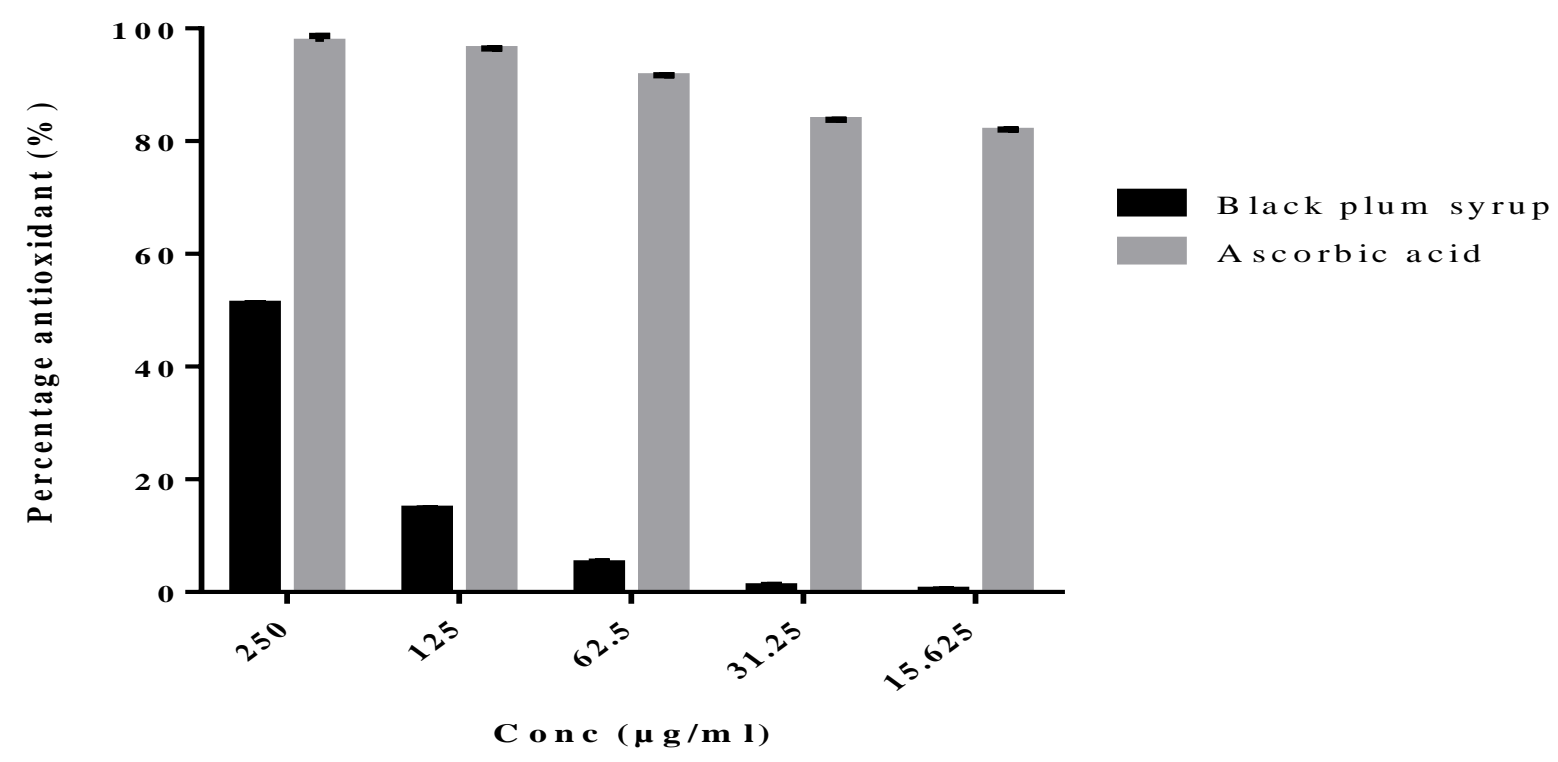

Figure 1: Result showing the antioxidant activity at different concentrations of Vitex doniana Fruit Syrup and the control (ascorbic acid)

To verify its folkloric use, there is the need to screen this plant for known bioactive secondary metabolites. Results of phytochemical analysis showed that Vitex doniana fruit syrup contained cardiac glycosides, terpenoids, tannins, flavonoids, steroids, saponins and alkaloids. Numerous and similar chemical groups have also been found in the Vitex doniana leaves [20]. Among these compounds, the tannins, flavonoids, steroids and terpenoids are already known for their antimicrobial activities [21]. According to Kunle and Egharevba [22], the secondary metabolites like saponins, flavonoids, resin, tannins, balsam and anthraquinone revealed in the phytochemical screening of the Vitex doniana sweet stem bark and leaf may be reason for some of the antimicrobial activities. The results obtained for the syrup were similar to the phytochemical analysis of $V$. agnus-castus, which showed the existence of steroids, glycosides, flavonoids, essential oil plus diterpenoids [23]. Also, like
Vitex doniana fruit syrup, all the phytochemicals exist in the ethanol extract of Vitex negundo leaves [24].

Antioxidant possessions of several extracts from countless plant life are of unlimited importance in both academia and the diet, ornamental and pharmacological manufacturing, ever since their potential use as natural condiments began from an increasing propensity to substitute man made antioxidant by natural ones. The antiradical abilities or free radical-scavenging capabilities of the syrup from fruitlets of $V$. doniana was measured by linkening with the activities of wellknown antioxidants, like ascorbic acid by $2,2^{\prime}-$ diphenyl-1-picrylhydrazyl (DPPH) radical assay. The lessening ability of DPPH radicals' creation was evaluated by the reduction in its absorbance at $517 \mathrm{~nm}$ induced by antioxidants. The end product of antioxidants on DPPH radical scavenging is believed to be because of their hydrogen bequeathing ability [25]. DPPH is an established 
unrestricted radical and receives an electron or hydrogen radical to turn into an unchanging diamagnetic molecule [26]. The scavenging capability of the syrup revealed a concentrationdependent activity profile. It improved with arise in their concentrations. Oxidative stress is associated in the pathophysiology of numerous ailments and conditions including cardiovascular disorders, diabetes, inflammatory conditions, liver diseases, ageing and cancer. Antioxidants could offer opposition against the oxidative stress by scavenging the unrestricted radicals and reactive oxygen components or by preventing the lipid peroxidation and therefore averting impairment. In the present study, the antioxidant potential of $V$. doniana fruit syrup was estimated. From the results in figure 1, the antioxidant activity of both the fruit syrup and ascorbic acid (control) showed increasing scavenging activity against DPPH with increase in concentration. After the assay, the $\mathrm{IC}_{50}$ value of the syrup was establish to be $245.8 \mu \mathrm{g} / \mathrm{ml}$ and that of ascorbic acid $2.175 \mu \mathrm{g} / \mathrm{ml}$, indicating that the syrup has negligible antioxidant activity comparable to ascorbic acid. Their antioxidant ability is largely because of their redox capabilities which make them behave as reducing agents, singlet oxygen quenchers and hydrogen donors. They could have too a metal chelating ability [27]. Likewise, radical scavenging capacity is one of the numerous mechanisms to give the complete activity, thus producing a synergistic result.

\section{Conclusion}

The plants considered here could be perceived as a possible source of valuable medicines. Vitex doniana fruit should also be considered as a source of edible syrup and their cultivation should be encouraged as it is endorsed for constant usage for dietary purpose, bearing in mind the variety of phytochemicals it contains.

\section{Acknowledgement}

Special thanks go to the Department of Chemistry, University of Benin, Benin City and to Prof. J.U. Iyasele of the Department of Chemistry, University of Benin, Benin City for his impactful, insightful and invaluable contributions.

\section{References}

1. L.D.C. Lopes, F. Albano, G.A.T. Laranja, L.M. Alves and L.F.M. Silva (2000), Toxicological Evaluation by in vitro and in vivo assays of an aqueous extract prepared from Echinodorus macrophyllus leaves, Toxicol. Lett., 116, 189-198.

2. B. Saad, H. Azaizeh, V. Abu-Hijleh and S. Said (2006), Safety of traditional Arab herbal Medicine, Evidence-Based Complement, Altern. Med, 3, 433-439.

3. W.J. Craig (1999), Health-promoting properties of common herbs, Am. J. Clin. Nutr., 70, 491-499.

4. J. Parekh and S. Chanda (2006), In-vitro Antimicrobial activities of extracts of Launaea Procumbens Roxb. (Labiateae), Vitis vinifera L. (Vitaceae) and Cyperus rotundus L. (Cyperaceae), Afr. J. Biomed. Res., 9, 89-93.

5. L. Cathrine and N.P. Nagarajan (2011), Preliminary phytochemical analysis and antibacterial Activity of leaf extracts of Vitex leucoxylon, Int. J. Curr. Pharm. Res., 3, 71-73.

6. P. Chandan, V. Kumar, K.P. Kamthan, U.B. Singh, S.K. Srivastava and R.B. Srivastava (2011), Antioxidant and antimicrobial activity of ethanol and water extracts of Cymbopogonj warancusa leaves, J. Appl. Pharm. Sci., 1, 68-72.

7. R.N. Okigbo (2001), Mycoflora within black plum (Vitex doniana) sweet fruits, Fruits, 56, 85-92.

8. C.O. Ochieng and B.O. Nandwa (2010), Proximate composition, Phenolic Content and Antioxidant Activities of three black plum (Vitex $s p$.) fruits: Preliminary results, J. Food Technol., 8(3), 118-125.

9. A.P. Enzo (2006), Review article: Phytochemicals from Traditional Medicinal Plants used in Composition of the Pulverized root of Cissus quadrangularis, Bioresearch, 1, 63-68.

10. O. Ladeji, F.V. Udoh and Z. Okoye (2005), Activity of aqueous extract of the bark of Vitex doniana on uterine muscle response to drugs, Phytotherapy Research, 19, 804-806.

11. H.M. Burkill (2000), Useful Plants of West Tropical Africa". Royal Botanic Garden Kew; 5(2), 272-275.

12. D. Hyson (2002), Health Benefits of Fruits and Vegetable, Scientific overview for health Professionals produce for better health foundation, Washington D.C., 20.

13. F.L. Sai (1997), Fruit and Vegetables in West Africa; Food and Agriculture 
Organisation of the United Nation, Rome pp. 5-6.

14. R. Black (2003), Micronutrient Deficiency: An Underlying Cause of Morbidity and Mortality, Bull, World Health Organisation, 8(2), 79.

15. B. Saad, H. Azaizeh, G. Abu-Hijleh and S. Said (2006), Safety of traditional Arab herbal Medicine. Evidence-Based Complement, Altern. Med., 3, 433-439.

16. A.E. Aiwonegbe, J.U. Iyasele and N.O. Izevbuwa (2018), Proximate Composition, Phytochemical and Antimicrobial Screening of Methanol and Acetone Extracts of Vitex doniana Fruit Pulp, Ife Journal of Science, 20(2), 207-212.

17. W. Hortwitz (1988), Sampling and preservation of sample for chemical examination", J. Assoc. Anal. Chem., 71, 224-247.

18. A. Sofowora (2008), Medicinal Plants and Traditional Medicine in Africa", 3rd edn., Spectrum Books Limited, Ibadan, Nigeria 199-204.

19. A. Adamu, K.B. Esievo, G. Ugbabe, S.E. Okhale and H.O. Egharevba (2018), High Performance Liquid Chromatographydiode array detection (HPLC-DAD) profiling, Antioxidant and antiproliferative activities of ethanol Leaf extract of Berlinia grandiflora (Vahl) Hutch \& Dalziel, Pharmacognosy and Phytotherapy, 10, 187-194.

20. N. Ejikeme and O.U. Henrietta (2010), Antimicrobial activities of leaf of Vitex doniana and Cajanus-cajanon on some bacteria, Researcher, 2, 37-47.
21. A.A. Owoseni, T.A. Ayanbamiji, Y.O. Ajayi and B. Ikeoluwa (2010), Antimicrobial and Phytochemical Analysis of leaves and bark extracts from Bridelia ferruginea, African Journal of Biotechnology, 9, 1031-1036.

22. O.F. Kunle and H.O. Egharevba (2009), Preliminary studies on Vernonia ambigua: Phytochemistry and Antimicrobial Screening of the Whole Plant, Ethnobotanical Leaflets, 13, 1216-1221.

23. A.R. Borges, J.R.A. Aires, T.M.M. Higino, M. Graças, F. Medeiros, A.M.G. Citó, J.A.D. Lopes and R.C.B.Q. Figueiredo (2012), Trypanocidal and cytotoxic Activities of essential oils from medicinal plants of Northeast of Brazil, Experimental Parasitology, 132, 123-128.

24. H.I. Raghavendra, B.N. Vijayananda, G.H. Madnumati and K. Vadlapadi (2010), Invitro Antioxidant Activity of Vitexnegundo L. leaf Extract, Chiang Mai J. Sci., 37(3), 489-497.

25. M. Leopoldini, N. Russo and M. Toscano (2011). The molecular basis of working Mechanism of

Natural Polyphenolic antioxidants, Food Chemistry, 125, 288-306.

26. N. Pattusamy and M. Changa (2017), Antioxidant activity of 3arylidene-4-piperidones in the 1,1Diphenyl-2-picrylhydrazyl scavenging assay, J. Taibah Univ Sci., 11, 40-45.

27. G. Mradu, S. Saumyakanti and M. Sohini (2012), HPLC profiles of standard phenolic compounds present in medicinal plants, Int. J. Pharmacog. Phytochem. Res., 4, 162-167. 